\title{
Evaluation of tablet computers for visual function assessment
}

\author{
Lakshmi Bodduluri $^{1}$ - Mei Ying Boon ${ }^{1}$ - Stephen J. Dain ${ }^{1}$
}

Published online: 22 March 2016

(C) Psychonomic Society, Inc. 2016

\begin{abstract}
Recent advances in technology and the increased use of tablet computers for mobile health applications such as vision testing necessitate an understanding of the behavior of the displays of such devices, to facilitate the reproduction of existing or the development of new vision assessment tests. The purpose of this study was to investigate the physical characteristics of one model of tablet computer (iPad mini Retina display) with regard to display consistency across a set of devices (15) and their potential application as clinical vision assessment tools. Once the tablet computer was switched on, it required about $13 \mathrm{~min}$ to reach luminance stability, while chromaticity remained constant. The luminance output of the device remained stable until a battery level of $5 \%$. Luminance varied from center to peripheral locations of the display and with viewing angle, whereas the chromaticity did not vary. A minimal $(1 \%)$ variation in luminance was observed due to temperature, and once again chromaticity remained constant. Also, these devices showed good temporal stability of luminance and chromaticity. All 15 tablet computers showed gamma functions approximating the standard gamma (2.20) and showed similar color gamut sizes, except for the blue primary, which displayed minimal variations. The physical characteristics across the 15 devices were similar and are known, thereby facilitating the use of this model of tablet computer as visual stimulus displays.
\end{abstract}

Lakshmi Bodduluri

1.bodduluri@student.unsw.edu.au

1 School of Optometry and Vision Science, University of New South Wales, Sydney, NSW 2052, Australia
Keywords iPad mini Retina display · Visual functions . Gamma function · Color gamut $\cdot$ Mobile health applications

Until recently, color cathode ray tube (CRT) monitors have been the most commonly used kind of visual display for applications in visual psychophysics laboratories. When developing any vision tests, the capabilities and limitations of the display technology must be understood in order to achieve accurate presentation of visual stimuli. Toward this purpose, CRT monitors have been carefully evaluated (Chioran et al. 1985; King-Smith, Vingrys, \& Benes, 1987; Mollon \& Baker, 1995; Sellers et al. 1986). However, numerous factors limit the utility of CRT monitors in vision research. First, the display and stimulus parameters are known to be affected by properties such as the consistency of phosphor color, linearity, spatial inhomogeneity, and temporal instability (Metha, Vingrys, \& Badcock, 1993; Mollon \& Baker, 1995). Second, the luminance and chromaticity of CRT monitors depend on spatial additivity, supply voltage, and individual monitor phosphor characteristics. These are known to vary over time, necessitating periodic calibration checks of individual monitors (Krantz, 2000; Mollon \& Baker, 1995; Olds, Cowan, \& Jolicœur, 1999). CRT monitors also require significant warm-up times (ranging from 45 to $180 \mathrm{~min}$ ) to reach luminance and chromatic stability (Metha et al. 1993; Mollon $\&$ Baker, 1995). Finally, a convex surface may lead to distortions or variations of luminance and chromaticity toward the edges (Kondoh, Hatazawa, \& Kozuka, 2001; Samei, 2002), causing difficulties in presenting accurate and consistent stimuli in vision experiments (Mollon \& Baker, 1995; Samei, 2002). Liquid crystal displays (LCD) and, to a lesser extent, plasma and organic light-emitting diodes have largely replaced CRTs for television displays and some computer workstation displays. However, CRT displays retain some temporal 
response advantages over LCDs, for displaying moving or flickering stimuli in vision experiments. Therefore, the LCD technology needs careful assessment of its temporal properties (Elze \& Tanner, 2012; Wang \& Nikolic, 2011), as they have immediate potential as displays for research laboratories (Lagroix, Yanko, \& Spalek, 2012), particularly for relatively static displays.

Along with the development of new methods to assess vision using personal-computer-based software; conventional vision tests have been replicated on CRT and LCD displays. For example, computerized tests that replicate the pseudoisochromatic plate test (Shin et al. 2014), FarnsworthMunsell 100 Hue test (Melamud, Simpson, \& Traboulsi, 2006; Shin, Park, Hwang, Wee, \& Lee, 2007) and the Martin Lantern test (Kapoor, Vats, \& Parihar, 2013), for color sensitivity assessment, Web-based color-naming tests (Moroney, 2003), and visual acuity and contrast sensitivity tests (Bach, 1996) are currently available. These computer and Web-based tests may attempt to address the issues of ambient lighting, color degradation, fading, and finger smudges. However, it is possible that the usefulness of such tests can detrimentally be affected by variations in display (such as luminance and chromaticity variations between devices or across the spatial extent of the display), warm-up times, and temporal stability. As a consequence, they may not be as accurate as the clinical tests (Dain \& Almerdef, 2016). In the controlled laboratory environment, researchers take care to calibrate the display periodically and ensure the temporal stability of the visual stimulus display before running any experiments. If luminance and chromatic contrast sensitivity tests are to be developed into useful tools outside the laboratory environment, it would be helpful to develop a simple, relatively inexpensive, and easy-to-administer portable vision assessment tool to investigate visual thresholds. However, these portable displays need to be assessed for their stability and consistency in luminance and chromaticity between devices and across the screen, and for their temporal characteristics.

The number of modern tablet computer users is increasing worldwide (Heggestuen, 2013). This trend has led to dramatic changes in the computer's roles across society in general, and in health care in particular (Acharya \& Kumar, 2012). For example, individuals are accustomed to monitor health and fitness data using applications such as the Fitbit Flex, Jawbone UP, pedometer, and so forth. A number of modern tablet computers are currently available that are amenable to the development of vision-testing apps providing high-quality vision assessment outside the traditional clinical or laboratory settings. The development of rapid, sensitive, and reliable mobile health solutions for assessing vision may address the need for specialized laboratory equipment and longer testing times. However, these tablet computers are not designed for psychophysics experiments or vision assessment tests. Researchers (Aslam et al. 2013; Tahir, Murray, Parry, \& Aslam, 2014) have reported the importance of certain physical characteristics (gamma function, stability of the display screen, and the effect of viewing angle) that should be considered while developing vision tests on tablet computers. With the improvements in display screen technology and resolution, it is now possible to use tablet computers such as iPads to assess contrast sensitivity (Dorr, Lesmes, Lu, \& Bex, 2013; Kollbaum, Jansen, Kollbaum, \& Bullimore, 2014) and to be used in visual psychophysics experiments (e.g., Turpin, Lawson, \& McKendrick, 2014). Portable tablet computers have the potential to be a useful self-monitoring vision assessment tool; however, there is little information about the possibility of using a tablet computer to test both color and contrast sensitivity. Therefore, the purpose of this study was to investigate the physical characteristics of one model of portable tablet computer (the iPad mini Retina display; Apple Inc., Cupertino, CA, USA) with regard to display consistency across a set of devices and for its potential suitability in the application of vision tests.

\section{Method}

A set of 15 iPad mini Retina display devices were purchased from a retail store and assessed for their physical characteristics and also for their consistency among devices (i.e., must each device be calibrated individually for vision testing, or is the between-device variability sufficiently small in practice?). The iPad mini Retina display has a display resolution of 2,048 $\times 1,536$ pixels at 326 pixels per inch and a screen size of 7.9 in. $(16 \times 12 \mathrm{~cm})$. The settings of the tablet computer were adjusted prior to the measurements, for consistency of testing and to minimize power drain due to processor use. Autolock was set to "never," auto-brightness was turned off, and brightness was set to its maximum setting of $100 \%$. All applications running in the background were closed. The display was cleaned using a micro-cloth to remove any fingerprints from the screen prior to measurement. The stability of the display, the effect of low battery on luminance, the effects of viewing angle and different screen locations on luminance and chromaticity, and the effects of temperature on luminance and chromaticity were assessed on three tablet computers. Temporal stability, gamma function, and color gamut size were assessed on all 15 tablet computers and evaluated.

The luminance and chromaticity measurements were obtained with the tablet on a stand at $45 \mathrm{deg}$ to the horizontal at $40 \mathrm{~cm}$ from the objective lens of a calibrated spectroradiometer (Model PR-730; Photo Research, Inc., Chatsworth, CA, USA). The optical axis of the PR-730 instrument was set perpendicular to the front surface of the tablet computer, as measured using an electronic inclinometer (Sola 
Electronic Spirit Level ENW60 [24 in.], Austria), and aimed at the center of the screen. The luminance measurements for the effect of low battery were taken by mounting the tablet computer perpendicular to the aperture of the goniophotometer (Optronik, Germany). The iPad mini device was programmed using a developer (i.e., programmer) application called "colorpicker" that allows input of RGB values (0-255) to display the desired output. The measurements were taken in a light-tight, unlit ISO 17025 (2005) accredited photometric laboratory with internal walls painted black ( $<0.01$ lux according to a Chroma Meter CL-200A; Konica Minolta, Osaka, Japan).

All instruments used to make photometric and spectral radiance measurements were calibrated using reference sources for which luminance intensity and spectral radiant intensity calibration values had been provided by the National Measurement Institute of Australia. For the reference white tiles, the reflectance (including spectral reflectance) calibration values had been provided by the National Research Council of Canada, and for the reference colored tiles, the spectral reflectance and chromaticity calibration values had been provided by the National Physical Laboratory of the UK. The procedures used are covered by the ISO 17035 accreditation as a calibration laboratory of the Optics \& Radiometry Laboratory by the National Association of Testing Authorities of Australia (Accredited Laboratory No. 1923; National Association of Testing Authorities, 2015). Wavelength accuracy was assessed using the spectral lines of mercury and neon spectral emission sources. The uncertainty of measurements will vary with each measurement, but the applicable least uncertainties listed in the scope of testing are:

Luminous intensity $1.0 \%$

Luminance $1.5 \%$ or $0.01 \mathrm{~cd} / \mathrm{m}^{2}$ (whichever is the greater) from $0.1 \mathrm{~cd} / \mathrm{m}^{2}$

Illuminance $0.9 \%$ in the range of 0.1 to 10,000 lux

Spectral radiance $0.7 \mathrm{~nm}$ in wavelength $3.3 \%$ at $380 \mathrm{~nm}$ falling to $1.0 \%$ at $555 \mathrm{~nm}$ and rising to $1.8 \%$ at $780 \mathrm{~nm}$ Chromaticity 0.0015

\section{Time required for stability of luminance and chromaticity output}

The time required to reach stable luminance and chromaticity from switch-on is an essential aspect of any display that is intended to be used for vision assessment. Vision assessment should only commence after stability has been reached. Three randomly selected tablet computers were left switched off for $24 \mathrm{~h}$, and the display testing was commenced with the devices at $100 \%$ charge level. Luminance and chromaticity were measured at 200-s intervals for a period of $80 \mathrm{~min}$ after switching on the device, for white (RGB: 255, 255, 255) and the three primaries [red (i.e., RGB: 255, 0, 0), green (RGB: 0, 255, 0), and blue (RGB: 0, 0, 255)].

\section{Effect of low battery state on luminance}

To understand how the luminance output of the tablet computers is affected when running them on battery charge only, the luminance outputs of the same three devices were measured using a goniophotometer. Luminance output was measured at the center of the display. The tablet computers were at $100 \%$ charge level at the start of the measurements, and the measurements continued until the battery state had reached $0 \%$ (automatic shutdown).

\section{Luminance and chromaticity at different screen locations on the tablet display and with viewing angle}

The luminance and chromaticity of the center and four peripheral locations (Fig. 1) were measured, for the same three tablet computers. Perpendicular and angled viewing at the tablet display were simulated; hence, the PR-730 instrument was set perpendicular to the measurement location on the display for the perpendicular viewing condition, and was angled from the center of the display to the measurement location for the angled viewing condition (see Fig. 1). The measurements were obtained for white and three primaries.

\section{Effect of temperature on luminance and chromaticity}

The tablet computer has an operating temperature range of 0 to $35^{\circ} \mathrm{C}$, according to the manufacturing specifications. Luminance and chromaticity were measured for the same three tablet computers assessed above at four different temperatures $\left(20,25,30\right.$, and $\left.35^{\circ} \mathrm{C}\right)$. For the temperatures 20 and $25^{\circ} \mathrm{C}$, the tablet computers were brought down to the test temperature by adjusting the room temperature and waiting until it (the room temperature) had stabilized (according to a Model WS241 Clock/Thermometer/ Hygrometer; Velleman, Inc., Gavere, Belgium). For the

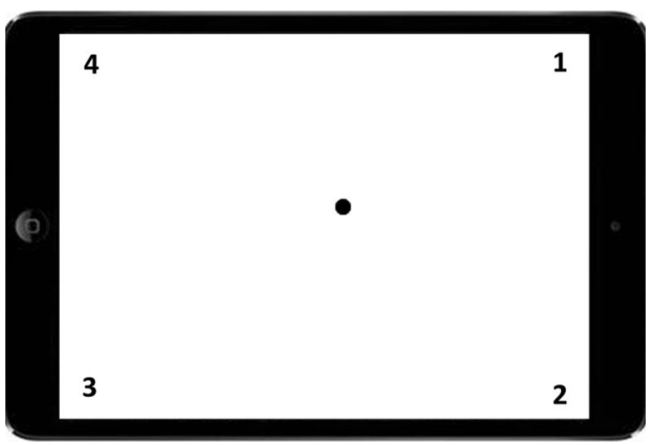

Fig. 1 Tablet computer showing the measurement locations (center and four peripheral locations) 
temperatures 30 and $35^{\circ} \mathrm{C}$, the tablet computers were brought to the test temperature in an oven with a glass door (LEBAC Horizontal Air Flow Oven; Laboratory Equipment Pty Ltd, Sydney, Australia). To achieve this, the oven was stabilized to the given test temperature $\left( \pm 0.5^{\circ} \mathrm{C}\right)$. Once the temperature had stabilized, the tablet computer was kept inside the oven with the door closed for measurements. The measurements were taken at the center of the screen (Fig. 1), with the PR-730 instrument kept perpendicular to the display, for the colors white, red, green, and blue.

\section{Gamma function}

Gamma is the relationship between the input value and the displayed luminance when viewed on screen (see, e.g., www. cgsd.com/papers/gamma_intro.html). It allows the vast range of luminances in a real-life scene to be compressed into the limited range of a visual display. It is a nonlinear operation of the form $L=V^{\gamma}$, where $L$ is the luminance of the display (expressed as a proportion of maximum), $V$ is the input value (expressed as a proportion of maximum), and $\gamma$ is the slope of the line of best fit in a $\log (L)$ versus $\log (V)$ function.

The gamma function helps us understand the range of programmable values for clinical vision testing. The iPad mini Retina display device has 8-bit resolution (0-255 pixel values). The luminance at the center of the screen was measured for nine grayscale intensity levels $(R=G=B=0,31,63$, $95,127,159,191,223$, and 255) between 0 and 255, at 32-bit intervals, for all 15 tablet computers.

\section{Color gamut}

The color gamut is normally expressed as the color space area enclosed by the three primaries (red, green, and blue) and is usually reported as a comparison with the area of the sRGB space. The sRGB specification is a default RGB color gamut adopted for computer displays (IEC, 1999), analogous to the default spaces used in television (e.g., EBU, 1975; NTSC, 1953).

Determining the color gamut (i.e., the range of colors that the device can generate) is important if the display is to be used to assess color sensitivity. It is also important for different devices to have similar-sized gamuts and between-device consistencies, to minimize the need for individual device calibration. The chromaticity coordinates for white and the three primaries were measured at the center of the screen for all 15 tablet computers, to plot their respective color gamuts.

\section{Temporal stability}

To assess the stability of the luminance and chromaticity output over time, all 15 tablet computers were tested after one month and one year from the initial date of measurements. These measurements were obtained for nine grayscale intensities, as described above in the section on the gamma function.

\section{Results}

Because the three tablet computers showed similar results, for ease of display (where individual device results are reported), the luminance and chromaticity are presented for one of the tablet computers (designated $i P a d 1$ ).

\section{Time required to stability of luminance and chromaticity}

Luminance Figure 2a shows the luminances of white and the three primaries as a function of time after the device was turned on (after being switched off for $24 \mathrm{~h}$ ). A total of 25 measurements were obtained over $80 \mathrm{~min}$. It took approximately $13 \mathrm{~min}$ to reach within $1 \%$ variation of the final luminance value.

The total percentage of variation in luminance output, measured over $80 \mathrm{~min}$, for white and the three primaries (red, green, and blue) were $0.0 \%, 0.8 \%, 0.2 \%$, and $1.9 \%$, respectively. Overall, there was a maximum of $1.9 \%$ variation in luminance output for the blue primary, whereas white and the other two primaries showed minimal variations. It took around $13 \mathrm{~min}$ for blue to be within $1 \%$ of the stable luminance values. These changes in luminance output were gradual and so small as to be below the limits of perception (Sacek, 2015).

Chromaticity Figure $2 b$ shows the variations in chromaticity with time for white and the three primaries for iPad 1. Table 1 shows the mean chromaticities along with their uncertainties for white and the three primaries. The variations in chromaticity were of the same order as the least uncertainty of the instrument (0.0015).

\section{Effect of low battery state on luminance}

The three tablet computers showed similar trends in terms of variation in luminance output over time. Luminance remained constant until the battery reached 5\% charge level and then showed a mean (and range across the three devices) reduction of $4.7 \%(3 \%-6 \%)$.

\section{Luminance and chromaticity at different locations on the tablet display}

As expected, we found differences in luminance at the peripheral locations as compared with the center. The data were plotted as the percentage changes in luminance from the brightest part of the screen (center). 


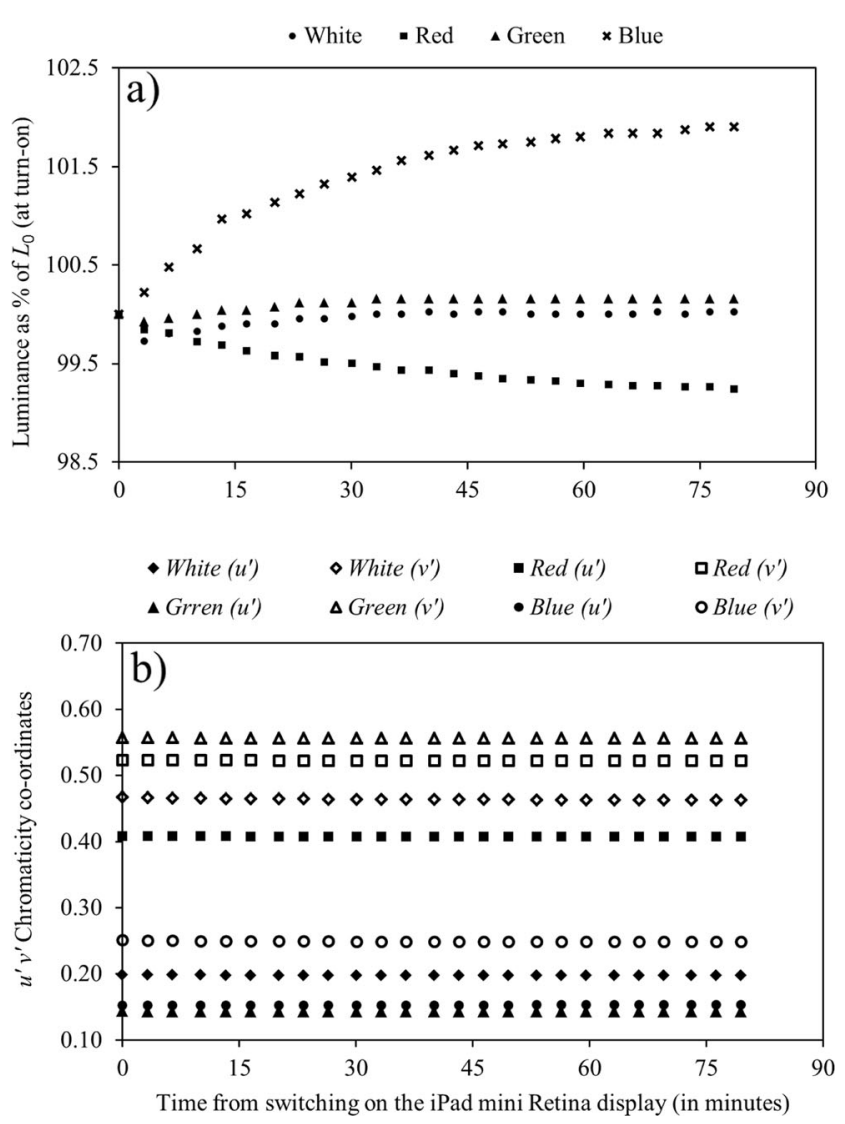

Fig. 2 Changes in (a) luminance (for white and the three primaries) and (b) colorimetric data $\left(u^{\prime} v^{\prime}\right.$ chromaticity coordinates for white and the three primaries; the filled and open symbols represent $u^{\prime}$ and $v^{\prime}$ chromaticity coordinates, respectively) as a function of time

Viewing perpendicularly The luminance values of white and the three primaries, for the center and four peripheral locations, in the condition simulating viewing the display screen perpendicularly, are given in Table 2. For white, averaged across the three tablet computers, the luminance of the peripheral locations varied from $3 \%$ to $11 \%$ as compared with the center. Of the four peripheral locations tested, the fourth corner (Fig. 1) showed the greatest reduction (11\%) in luminance compared with the center. However, variation in the chromaticities in the peripheral locations, as compared with center,

Table 1 Mean (with uncertainties) $u^{\prime} v^{\prime}$ chromaticity coordinates for white and the three primaries

\begin{tabular}{lllll}
\hline & \multicolumn{2}{l}{ Mean } & & \multicolumn{2}{l}{ RMS of $S D$ and Instrument Uncertainty } \\
\cline { 2 - 3 } \cline { 5 - 6 } & $u^{\prime}$ & $v^{\prime}$ & & $u^{\prime}$ \\
\hline White & 0.197 & 0.464 & 0.0015 & 0.0016 \\
Red & 0.408 & 0.523 & 0.0015 & 0.0015 \\
Green & 0.143 & 0.556 & 0.0015 & 0.0015 \\
Blue & 0.152 & 0.249 & 0.0015 & 0.0015 \\
\hline
\end{tabular}

Table 2 Luminance values of center and four peripheral locations for white and the three primaries (viewed perpendicularly) for three tablet computers

\begin{tabular}{lllllll}
\hline & iPad No & Center & Corner 1 & Corner 2 & Corner 3 & Corner 4 \\
\hline \multirow{2}{*}{ White } & iPad 1 & 403 & 404 & 404 & 380 & 371 \\
& iPad 2 & 434 & 400 & 401 & 402 & 388 \\
& iPad 3 & 413 & 401 & 415 & 369 & 359 \\
Red & $i$ Pad 1 & 87.4 & 87.5 & 87.5 & 81.3 & 79.8 \\
& $i$ iPad 2 & 89.7 & 83.1 & 83.3 & 82.7 & 79.7 \\
& $i P a d$ 3 & 90.1 & 87.4 & 89.6 & 78.8 & 76.7 \\
Green & $i P a d$ 1 & 256 & 255 & 255 & 240 & 235 \\
& $i P a d$ 2 & 279 & 259 & 259 & 260 & 251 \\
& $i P a d$ 3 & 261 & 251 & 260 & 233 & 226 \\
Blue & $i P a d$ 1 & 60.7 & 60.8 & 60.5 & 57.7 & 55.8 \\
& $i P a d$ 2 & 62.9 & 58.0 & 58.5 & 59.6 & 57.4 \\
& $i P a d$ 3 & 63.5 & 62.1 & 63.3 & 57.1 & 55.6 \\
\hline
\end{tabular}

was within 1.5 times the instrument's least uncertainty (0.0023) (Fig. 3).

Viewing at an angle (simulating real world scenario) The luminance values of white and the three primaries for the center and four peripheral locations, in the condition simulating viewing the display at an angle, are given in Table 3 . For this condition, the difference in luminance of white in peripheral locations as compared with the center, after averaging across the three tablet computers, varied from $6 \%$ to $17 \%$. Of the four peripheral locations tested, the third corner (Fig. 1) showed the greatest reduction (17\%) in luminance compared with the center. However, variation in the chromaticities in the peripheral locations, as compared with center, was within 1.5 times the instrument's least uncertainty (0.0023; Fig. 4).

\section{Effect of temperature on luminance and chromaticity}

As has been shown in the literature, the luminance output decreased as the temperature increased (Dalapati, Manik, \& Basu, 2013; Zhang, Li, Zhang, \& Xi, 2008), except for the blue primary. Figure 5 shows the variations in luminance as a function of temperature, plotted as percentages of the luminance at $20^{\circ} \mathrm{C}$, for white and the three primaries. The luminance values decreased as the temperature increased, for white, red, and green, whereas the blue primary showed an initial decrease in luminance from 20 to $25{ }^{\circ} \mathrm{C}$, and then increased from 25 to $35{ }^{\circ} \mathrm{C}$. However, the mean percentage of variation was within $1 \%$. The mean (with $95 \%$ confidence interval $[\mathrm{CI}])$ luminances for white and the three primaries were $306(1.6), 63.9(0.6), 195(0.9)$, and $46.3(0.3) \mathrm{cd} / \mathrm{m}^{2}$, respectively. 
Fig. 3 The $u^{\prime} v^{\prime}$ chromaticity coordinates for (a) white and for the three primaries - (b) red, (c) green, and (d) blue - for five locations (viewed perpendicularly) for iPad 1

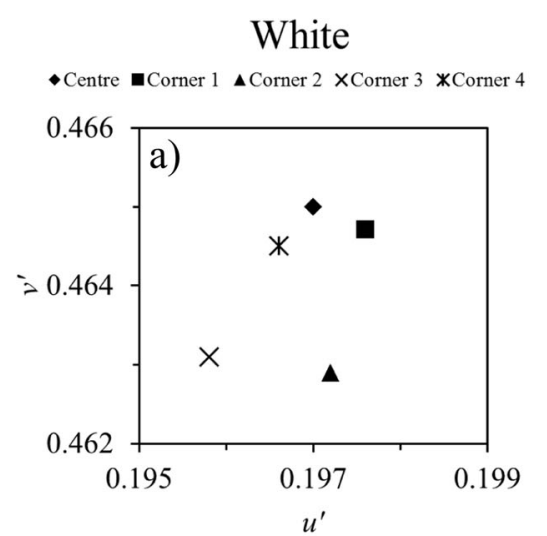

Green

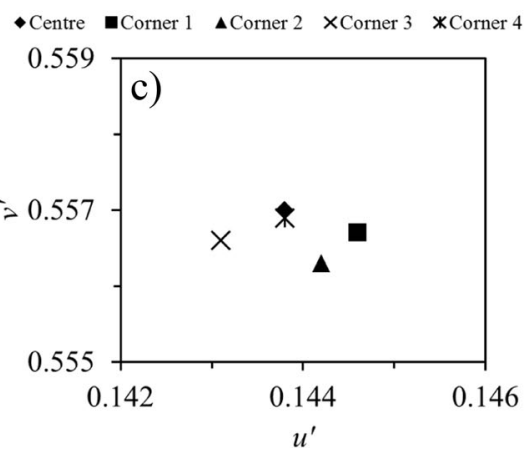

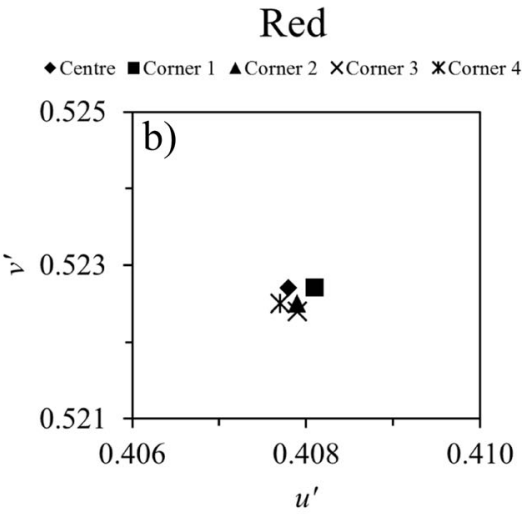

Blue

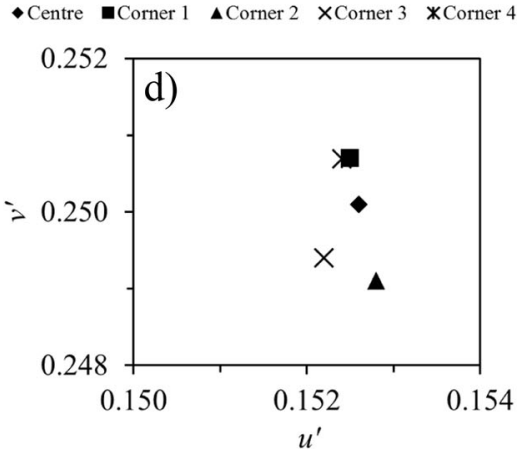

Table 4 shows the chromaticity coordinates for white and the three primaries for the four test temperatures. Within the normal room temperature range $\left(20-30{ }^{\circ} \mathrm{C}\right)$, there was no measurable change in the chromaticity for white or for the three primaries. Also, the variation in chromaticities across the four test temperatures was similar to the least uncertainty of the instrument (.0015). Therefore, these minor variations in chromaticity may not have any impact on vision assessment.

\section{Gamma function and color gamut}

To understand whether one stimulus look-up table can be extrapolated to a number of devices of the same make and model, we characterized and compared the gamma functions and color gamuts of all 15 tablet computers.

Gamma function Figure 6 shows the gamma function of one of the tablet computers. The relationship between the input intensity level and the output was nonlinear - that is, a change in input does not translate into an equivalent change in the luminance output - and was measured to be very close to that of the standard gamma (2.20). The gamma functions of the 15 tablet computers (Table 5), calculated by plotting the log of the intensity scales against the log of brightness, ranged from 2.13 to 2.21 , with a mean gamma of 2.18 .

The mean (and 95\% CIs) (for all 15 tablet computers) luminance values for white, red, green, and blue were $410 \mathrm{~cd} / \mathrm{m}^{2}$ (401-420), $87.1 \mathrm{~cd} / \mathrm{m}^{2}$ (85.1-89.1), $261 \mathrm{~cd} / \mathrm{m}^{2}$ (253-268), and $61.2 \mathrm{~cd} / \mathrm{m}^{2}$ (59.4-63.0), respectively. Of the 15 tablet computers, the 10th tablet showed consistently low luminance values (see Table 6).

Color gamut Figure 7 shows the gamut of colors that can be displayed on the tablet computer, plotted in the 1976 CIE $u^{\prime} v^{\prime}$ color space. The $u^{\prime} v^{\prime}$ chromaticity coordinates of the three primaries were used to determine the color gamut, which

Table 3 Luminance values of center and four peripheral locations for white and the three primaries (viewed at an angle) for three tablet computers

\begin{tabular}{|c|c|c|c|c|c|c|}
\hline & iPad No & Center & Corner 1 & Corner 2 & Corner 3 & Corner 4 \\
\hline \multirow[t]{3}{*}{ White } & iPad 1 & 403 & 390 & 400 & 336 & 337 \\
\hline & iPad 2 & 434 & 366 & 388 & 378 & 370 \\
\hline & iPad 3 & 413 & 384 & 393 & 322 & 336 \\
\hline \multirow[t]{3}{*}{ Red } & ¡Pad 1 & 87.4 & 84.5 & 87.1 & 73.7 & 72.7 \\
\hline & $i \operatorname{Pad} 2$ & 89.7 & 75.8 & 80.5 & 78.2 & 76.5 \\
\hline & iPad 3 & 90.1 & 83.4 & 85.7 & 69.2 & 72.4 \\
\hline \multirow[t]{3}{*}{ Green } & ¡Pad 1 & 256 & 245 & 252 & 217 & 213 \\
\hline & iPad 2 & 279 & 237 & 251 & 244 & 239 \\
\hline & iPad 3 & 261 & 240 & 247 & 203 & 211 \\
\hline \multirow[t]{3}{*}{ Blue } & iPad 1 & 60.7 & 59.0 & 60.3 & 51.7 & 50.8 \\
\hline & iPad 2 & 62.9 & 53.8 & 56.3 & 56.9 & 54.6 \\
\hline & iPad 3 & 63.5 & 60.0 & 60.5 & 49.7 & 51.7 \\
\hline
\end{tabular}


Fig. 4 The $u^{\prime} v^{\prime}$ chromaticity coordinates for (a) white and for the three primaries - (b) red, (c) green, and (d) blue - for five locations (viewed at an angle) for iPad 1
White

-Centre $\mathbf{a}$ Corner $1 \Delta$ Corner $2 \times$ Corner 3 *Corner 4

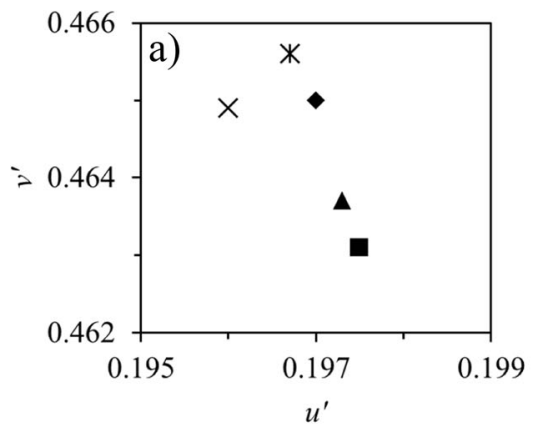

Green

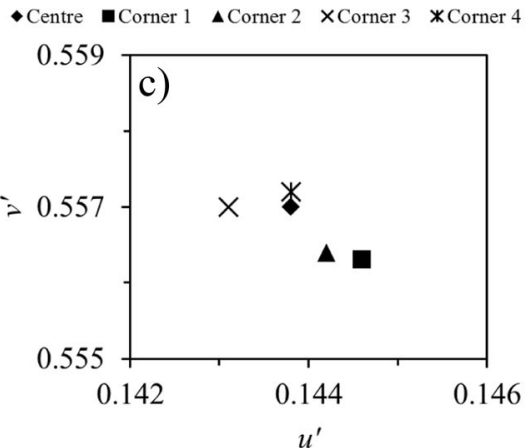

Red

$\downarrow$ Centre $\mathbf{a}$ Corner $1 \Delta$ Corner $2 \times$ Corner $3 *$ Corner 4

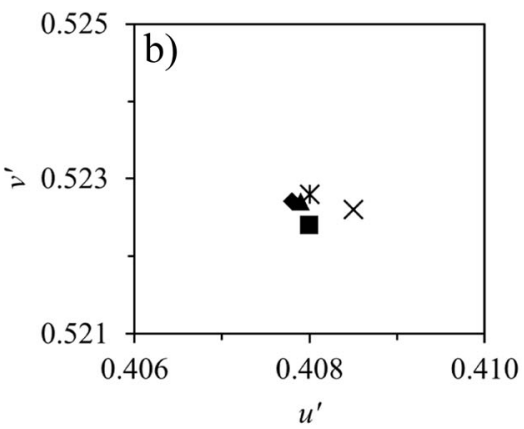

Blue

- Centre Corner $1 \quad \Delta$ Corner $2 \times$ Corner 3 xCorner 4

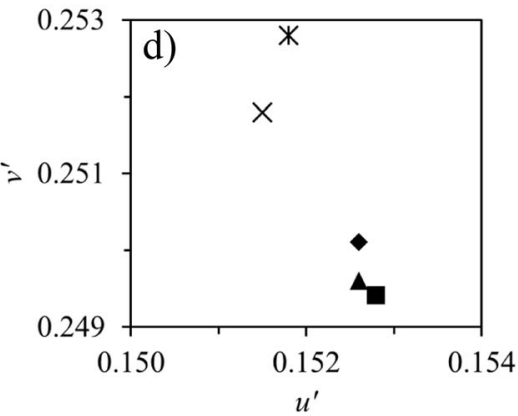

was calculated to be $63 \%$ of the standard sRGB. Figure 8 shows the $u v^{\prime}$ chromaticity coordinates for white $(\mathrm{R}=\mathrm{G}=$ $\mathrm{B}=255)$ and the three primaries $(\mathrm{R}, \mathrm{G}, \mathrm{B}=255,0,0 ; 0,255,0$; and $0,0,255)$ for all 15 tablet computers. We observed a slight variation in the chromaticities for the blue primary, whereas the chromaticities for white, red, and green were consistent across all 15 tablet computers. The color gamut sizes calculated as percentages of sRGB ranged from $60 \%$ to $66 \%$ across the 15 tablet computers, with a mean color gamut size of $62 \%$.

Table 7 shows the mean (and 95\% CIs) chromaticities (of all 15 tablet computers) for white and the three

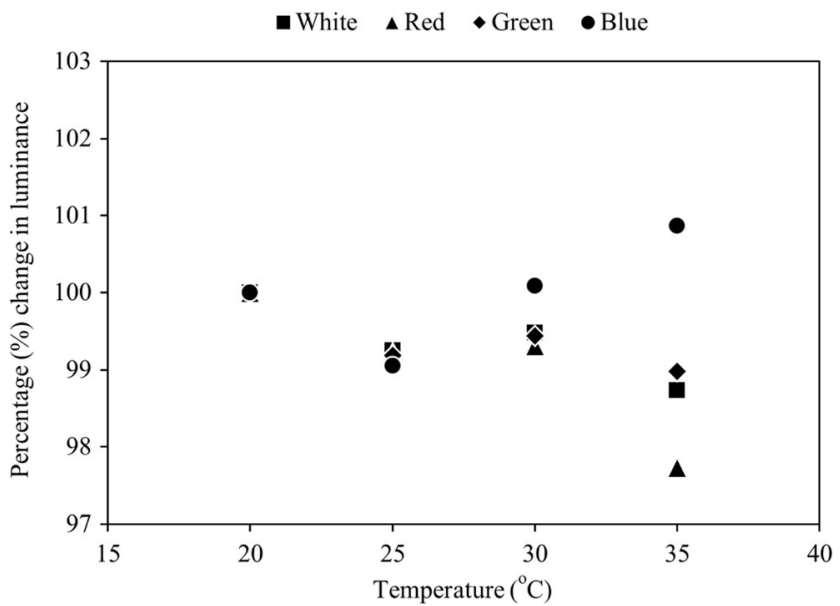

Fig. 5 Changes in luminance output as a function of temperature for white and the three primaries primaries. The variations in the chromaticities for white, red, and green across the 15 tablet computers were within the least uncertainty of the instrument (.0015), whereas the variation in the blue primary was about three times the instrument's least uncertainty (.0045).

\section{Temporal stability}

Figure 9 shows the luminance outputs of one of the tablet computers, measured after one month and one year from the initial date of the measurements. The measurements lie on lines with slopes of 1.01 and 0.99 for one month and one year, respectively, indicating very minimal variations in luminance over time. The mean chromaticities of the display changed from $\left(u^{\prime} v^{\prime}\right)_{\mathrm{CIE}}=(.199, .460)$ to $\left(u^{\prime} v^{\prime}\right)_{\mathrm{CIE}}=(.199, .457)$ and

Table 4 The $u^{\prime} v^{\prime}$ chromaticity coordinates for four test temperatures, for white $(R=G=B=255)$ and the three primaries $(R=255, G=255$, and $\mathrm{B}=255)$

\begin{tabular}{|c|c|c|c|c|c|c|c|c|}
\hline \multirow[t]{2}{*}{${ }^{\circ} \mathrm{C}$} & \multicolumn{2}{|l|}{ White } & \multicolumn{2}{|l|}{ Red } & \multicolumn{2}{|l|}{ Green } & \multicolumn{2}{|l|}{ Blue } \\
\hline & $u^{\prime}$ & $v^{\prime}$ & $u^{\prime}$ & $v^{\prime}$ & $u^{\prime}$ & $v^{\prime}$ & $u^{\prime}$ & $v^{\prime}$ \\
\hline 20 & 0.194 & 0.466 & 0.405 & 0.522 & 0.142 & 0.557 & 0.151 & 0.253 \\
\hline 25 & 0.194 & 0.466 & 0.405 & 0.522 & 0.142 & 0.557 & 0.151 & 0.253 \\
\hline 30 & 0.194 & 0.466 & 0.405 & 0.522 & 0.142 & 0.557 & 0.151 & 0.252 \\
\hline 35 & 0.193 & 0.463 & 0.404 & 0.522 & 0.142 & 0.556 & 0.152 & 0.250 \\
\hline
\end{tabular}




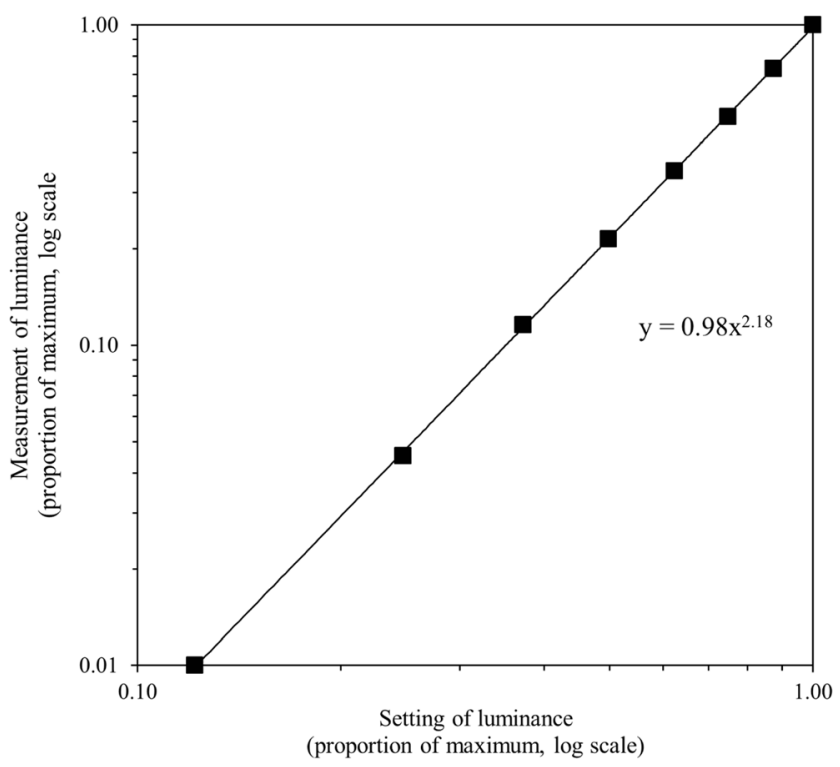

Fig. 6 Gamma function of one of the tablet computers (iPad 1)

$(.196, .456)$ on the initial date, after one month, and after one year, respectively.

\section{Discussion}

In the present study, we evaluated the possibility of using one of the currently available tablet computers (an iPad mini Retina display) for the purposes of portable self-monitoring vision assessment, by evaluating its physical characteristics. This study provided important information about the display's behavior, which will be essential while developing vision tests on such tablet computers or designing visual stimuli to assess specific visual functions. Of the physical characteristics

Table 5 Gamma functions of all 15 tablet computers

\begin{tabular}{ll}
\hline iPad Number & Gamma Function \\
\hline iPad1 & 2.18 \\
iPad2 & 2.12 \\
iPad3 & 2.20 \\
iPad4 & 2.14 \\
iPad5 & 2.17 \\
iPad6 & 2.16 \\
iPad7 & 2.20 \\
iPad8 & 2.20 \\
iPad9 & 2.18 \\
iPad10 & 2.20 \\
iPad11 & 2.18 \\
iPad12 & 2.20 \\
iPad13 & 2.18 \\
iPad14 & 2.21 \\
iPad15 & 2.13 \\
\hline
\end{tabular}

Table 6 Luminance values for white and the three primaries of all 15 tablet computers

\begin{tabular}{lllll}
\hline & White & Red & Green & Blue \\
\hline iPad 1 & 403 & 87.4 & 256 & 60.7 \\
iPad 2 & 434 & 89.7 & 279 & 62.9 \\
iPad 3 & 413 & 90.1 & 261 & 63.5 \\
iPad 4 & 428 & 87.3 & 279 & 60.3 \\
iPad 5 & 409 & 84.4 & 261 & 60.2 \\
iPad 6 & 439 & 92.1 & 282 & 64.6 \\
iPad 7 & 421 & 91.3 & 265 & 65.8 \\
iPad 8 & 415 & 87.1 & 267 & 59.9 \\
iPad 9 & 412 & 89.9 & 262 & 59.6 \\
iPad 10 & 360 & 77.2 & 222 & 56.2 \\
iPad 11 & 403 & 86.0 & 254 & 59.4 \\
iPad 12 & 399 & 85.7 & 245 & 64.7 \\
iPad 13 & 413 & 89.6 & 261 & 62.6 \\
iPad 14 & 413 & 87.5 & 262 & 65.3 \\
iPad 15 & 392 & 81.1 & 254 & 52.4 \\
\hline
\end{tabular}

assessed, the effective time until luminance output stabilized was $13 \mathrm{~min}$, which was comparable with that reported by Aslam et al. (2013) as 15 min on a 3rd-generation iPad. The warm-up time (13 $\mathrm{min}$ ) reported in this study was considerably lower than those with CRT monitors (45-180 min). The luminance output reduced by about $5.5 \%$ at a battery level of $5 \%$, which is in contrast to that reported by both Aslam et al. (2013) and Tahir et al. (2014), who reported that the luminance values on their devices remained stable until the automatic device shutdown.

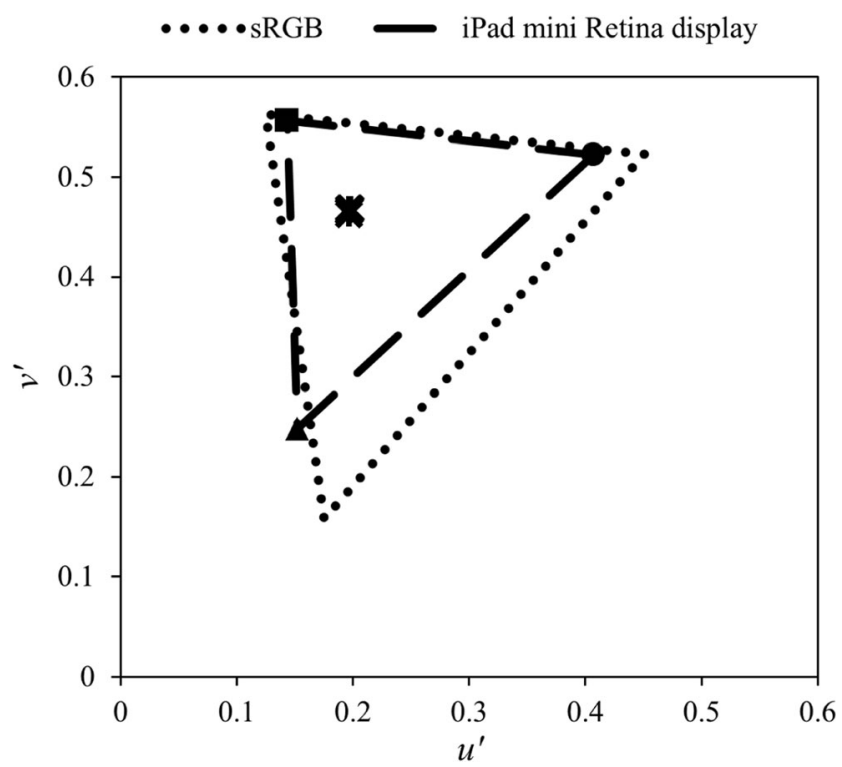

Fig. 7 Color gamut of iPad 1, plotted in $1976 \mathrm{CIE} u^{\prime} v^{\prime}$ color space. The dotted triangle represents the sRGB gamut, and the dashed triangle represents the gamut of the tablet computer under test 


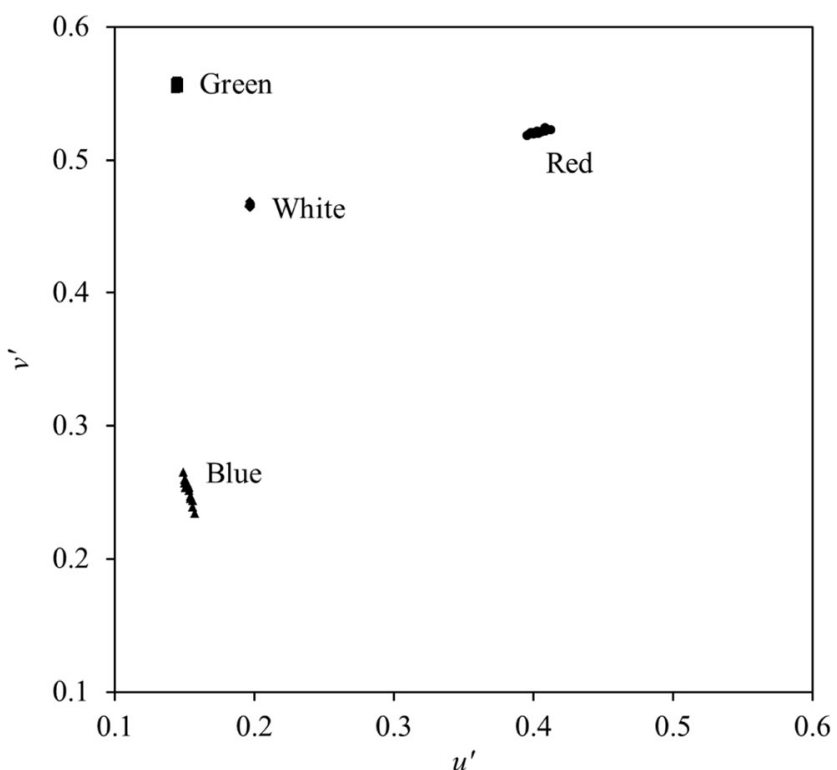

Fig. 8 The $u^{\prime} v^{\prime}$ chromaticity coordinates for white and the three primaries of all 15 tablet computers

Aslam et al. (2013) reported maximum luminance variations (from center to periphery) of $23 \%$ and $29 \%$ for conditions of viewing straight at the display and viewing at an angle, respectively. In contrast, our study reported less than a $20 \%$ variation in luminance at the periphery as compared with the center for both viewing conditions, which is also less than the value reported in CRTs (30\%; Samei, 2002). This may, in part, be due to the smaller screen of the iPad mini, and it remains to be seen whether this would be the case with larger screens, including with the full-sized iPad. For the luminance levels of the iPad, previous studies on the effects of luminance/illuminance on discrimination thresholds have shown that the discrimination threshold is independent of the total amount of light (e.g., Bowman \& Cole, 1980; Knoblauch et al., 1987; Verriest, Buyssens, \& Vanderdonck, 1963; Verriest, Vandevyvere, \& Vanderdonck, 1962). Therefore, the minor variation we observed between iPad minis will have no measurable effect on results. Color discrimination results that have varied with different light levels have required much lower light levels (e.g., Bowman, 1978;

Table 7 Mean (and 95\% confidence intervals) $u^{\prime} v^{\prime}$ chromaticity coordinates for white $(R=G=B=255)$ and the three primaries $(R=$ $255, \mathrm{G}=255$, and $\mathrm{B}=255$ ) for all 15 tablet computers

\begin{tabular}{llllll}
\hline & \multicolumn{2}{l}{ Mean } & & & \multicolumn{2}{l}{$95 \%$ Confidence Interval } \\
\cline { 2 - 3 } \cline { 5 - 6 } & $u^{\prime}$ & $v^{\prime}$ & & $u^{\prime}$ & $v^{\prime}$ \\
\hline White & 0.197 & 0.467 & & \pm .0002 & \pm .0008 \\
Red & 0.408 & 0.523 & & \pm .0007 & \pm .0004 \\
Green & 0.144 & 0.557 & & \pm .0003 & \pm .0007 \\
Blue & 0.153 & 0.249 & & \pm .0012 & \pm .0040 \\
\hline
\end{tabular}
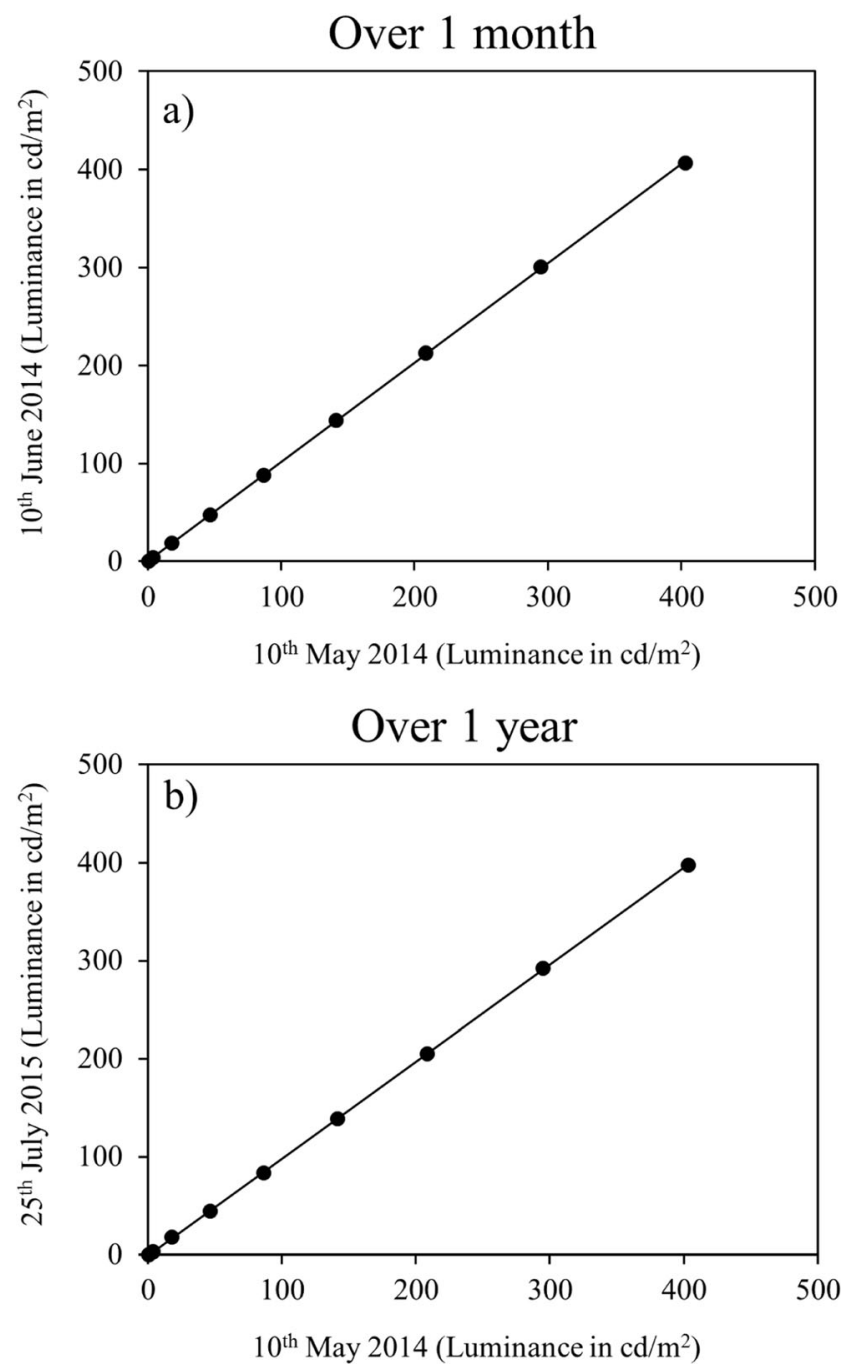

Fig. 9 Temporal stability of luminance output over (a) one month and (b) one year, for iPad 1

Dain, Pereira, Palmer, Lewis, \& Hammond, 1980; Dain, Scase, \& Foster, 1991; Smith, Van Everdingen, \& Pokorny, 1991). In the case of detection thresholds, the variation in luminance will apply to both the background and increment if the background luminance is within the Weber region (Ekman, 1959):

Threshold $=\frac{\Delta L}{L}=k=\frac{n \Delta L}{n L}$,

where $\Delta L$ is the luminance increment at threshold; $L$ is the background luminance; $k$ is a constant, about $1 \%$ for achromatic thresholds and a $2^{\circ}$ stimulus; and $n$ is any multiplier (within limits).

The present study showed minimal variations (1\%) in luminance and chromaticity with temperature and over time (temporal stability). We also reported that the gamma functions and color gamuts were comparable across our 15 tablet 
computers. Implications of these findings suggest that similar stimulus parameters may be expected from different devices of the same make and model, and that a single stimuli look-up table may be extrapolated to all these tablet computers to assess specific vision functions, with confidence that the output is as required.

However, it may not be possible to apply these findings to different generations of iPads or to other Android-/Windowsbased tablet computers. This is due to the fact that these devices have different manufacturing specifications that vary in their display screen technologies (such as LCD, LED, or OLED), display resolutions, sizes, and color outputs. Thus, it is important to note that devices of different makes and models need to be calibrated on an individual basis (if the devices are not of the same make and model) to understand their display performance and also their suitability as displays for vision assessment. For instance, Dain, Kwan, and Wong (2016) showed that a single color look-up table could not be used for the iPhone 4s, iPhone 5, Samsung Galaxy S3, and Samsung Galaxy S4.

In summary, the way in which a tablet computer is calibrated and used depends entirely on the mode of application. Although future studies will be needed to evaluate and understand the suitability of these tablet computers as displays for moving stimuli for vision research, knowledge of the aspects of the tablet computers' performance we have examined allows us to make recommendations regarding their use in vision assessment with relatively static stimuli.

Auhor note We thank Lois Wang, a vision science student, for help with the measurement procedures. We declare no competing interests.

\section{References}

Acharya, D., \& Kumar, V. (2012). Mobile broadband-based healthcare management: Advantages, issues and challenges. International Journal of Computers in Healthcare, 1, 254-268. doi:10.1504/ IJCIH.2012.046998

Aslam, T. M., Murray, I. J., Lai, M. Y. T., Linton, E., Tahir, H. J., \& Parry, N. R. A. (2013). An assessment of a modern touch-screen tablet computer with reference to core physical characteristics necessary for clinical vision testing. Journal of the Royal Society Interface, 10, 20130239. doi:10.1098/rsif.2013.0239

Bach, M. (1996). The Freiburg Visual Acuity Test—Automatic measurement of visual acuity. Optometry \& Visual Science, 73, 49-53. doi: 10.1097/00006324-199601000-00008

Bowman, K. J. (1978). The effect of illuminance on colour discrimination in senile macular degeneration. Modern Problems in Ophthalmology, 19, 71-76.

Bowman, K. J., \& Cole, B. L. (1980). A recommendation for illumination of the Farnsworth-Munsell 100-hue test. American Journal of Optometry and Physiological Optics, 57, 839-843.

Chioran, G., Sellers, K., Benes, S., Lubow, M., Dain, S., \& King-Smith, P. E. (1985). Color mixture thresholds measured on a color television-A new method for analysis, classification and diagnosis of neuro-ophthalmic disease. Documenta Ophthalmologica, 61, 119135. doi:10.1007/BF00170720

Dain, S. J., \& Almerdef, A. (in press). Colorimetric evaluation of iPhone apps for colour vision tests based the Ishihara test. Clinical and Experimental Optometry.

Dain, S. J., Kwan, B., \& Wong, L. (2016). Consistency of color representation in smart phones. Journal of the Optical Society of America A, 33, A300-A305. doi:10.1364/JOSAA.33.00A300

Dain, S. J., Pereira, S. M., Palmer, B., Lewis, P., \& Hammond, T. (1980). Illuminance and the FM 100 hue test. In G. Verriest (Ed.), Colour Vision Deficiencies V (pp. 162-163). Bristol: Adam Hilger.

Dain, S. J., Scase, M., \& Foster, D. (1991). An assessment of the "mesopization" model of blue-yellow colour vision defects. In Colour Vision Deficiencies X (pp. 187-197). Dordrecht: Kluwer Academic Publishers.

Dalapati, P., Manik, N., \& Basu, A. (2013). Effect of temperature on the intensity and carrier lifetime of an AlGaAs based red light emitting diode. Journal of Semiconductors, 34, 092001. doi:10.1088/16744926/34/9/092001

Dorr, M., Lesmes, L. A., Lu, Z.-L., \& Bex, P. J. (2013). Rapid and reliable assessment of the contrast sensitivity function on an iPad. Investigative Ophthalmology and Visual Science, 54, 7266-7273. doi:10.1167/iovs.13-11743

EBU. (1975). Standard for chromaticity tolerances for studio monitors (Technical Report No. 3213-E). Geneva, Switzerland: Author.

Ekman, G. (1959). Weber's law and related functions. Journal of Psychology, 47, 343-352.

Elze, T., \& Tanner, T. G. (2012). Temporal properties of liquid crystal displays: Implications for vision science experiments. PLoS ONE, 7, e44048. doi:10.1371/journal.pone.0044048

Heggestuen, J. (2013). One in every 5 people in the world own a smartphone, one in every 17 own a tablet [Chart]. Retrieved 24 June, 2014, from www.businessinsider.com.au/smartphone-andtablet-penetration-2013-10

IEC. (1999). Multimedia systems and equipment-colour measurement and management-part 2-1: Colour management-default RGB colour space-sRGB (Specification No. IEC 61966-2-1). Geneva, Switzerland: Author.

ISO/IEC. (2005). ISO/IEC 17025: General requirements for the competence of testing and calibration laboratories. Geneva, Switzerland: ISO.

Kapoor, G., Vats, D. P., \& Parihar, J. K. (2013). Development of computerized color vision testing as a replacement for Martin Lantern. Medical Journal of the Armed Forces in India, 69, 11-15. doi:10. 1016/j.mjafi.2012.07.023

King-Smith, P. E., Vingrys, A. J., \& Benes, S. C. (1987). Visual thresholds measured with color video monitors. Color: Research \& Application, 12, 73-80. doi:10.1002/col.5080120205

Knoblauch, K., Saunders, F., Kusuda, M., Hynes, R., Podgor, M., Higgins, K. E., \& De Monasterio, F. M. (1987). Age and illuminance effects in the Farnsworth-Munsell 100-hue test. Applied Optics, 26, 1441-1448.

Kollbaum, P. S., Jansen, M. E., Kollbaum, E. J., \& Bullimore, M. A. (2014). Validation of an iPad test of letter contrast sensitivity. Optometry and Vision Science, 91, 291-296. doi:10.1097/opx. 0000000000000158

Kondoh, H., Hatazawa, K., \& Kozuka, T. (2001). The performance of general-purpose colour CRT monitors in PACS environment. Computer Methods and Programs in Biomedicine, 66, 63-68. doi: 10.1016/S0169-2607(01)00136-5

Krantz, J. (2000). Tell me, what did you see? The stimulus on computers. Behavior Research Methods, Instruments, \& Computers, 32, 221229. doi:10.3758/BF03207787

Lagroix, H. E., Yanko, M. R., \& Spalek, T. M. (2012). LCDs are better: Psychophysical and photometric estimates of the temporal 
characteristics of CRT and LCD monitors. Attention, Perception, \& Psychophysics, 74, 1033-1041. doi:10.3758/s13414-012-0281-4

Melamud, A., Simpson, E., \& Traboulsi, E. I. (2006). Introducing a new computer-based test for the clinical evaluation of color discrimination. American Journal of Ophthalmology, 142, 953-960.e952. doi: 10.1016/j.ajo.2006.07.027

Metha, A., Vingrys, A., \& Badcock, D. (1993). Calibration of a color monitor for visual psychophysics. Behavior Research Methods, Instruments, \& Computers, 25, 371-383. doi:10.3758/BF03204528

Mollon, J.D., \& Baker, M. R. (1995). The use of CRT displays in research on colour vision. In B. Drum, A. J. Adams, C. R. Cavonius, S. J. Dain, G. Haegerstrom-Portnoy, K. Kitahara, ... E. Zrenner (Eds.), Colour vision deficiencies XII (Vol. 57, pp. 423-444). Amsterdam, The Netherlands: Springer Netherlands.

Moroney, N. (2003). Unconstrained web-based color naming experiment. In R. Eschbach \& G. G. Marcu (Eds.), Color imaging VIII: Processing, hardcopy, and applications (pp. 36-46). Paris, France: SPIE. doi:10.1117/12.472013

National Association of Testing Authorities. (2015). Lab scope details. Retrieved 31 July, 2015, from www.nata.com.au/nata/scopeinfo/? key $=1916$

NTSC. (1953). Report and Reports of Panel No. 11, 11-A, 12-19: with Some supplementary references cited in the Reports, and the Petition for adoption of transmission standards for color television before the Federal Communications Commission.

Olds, E. S., Cowan, W. B., \& Jolicœur, P. (1999). Effective color CRT calibration techniques for perception research. Journal of the Optical Society of America A, 16, 1501-1505. doi:10.1364/ JOSAA.16.001501

Sacek, V. (2015). Eye intensity response, contrast sensitivity. Retrieved 28th July, 2015, from http://www.telescope-optics.net/eye intensity_response.htm\#frequency

Samei, E. (2002). New developments in display quality control. In B. R. Siegel \& J. Carrino (Eds.), Quality assurance and quality control in the digital imaging department (pp. 71-82). Great Falls, VA: Society for Computer Applications in Radiology.

Sellers, K. L., Chioran, G. M., Dain, S. J., Benes, S. C., Lubow, M., Rammohan, K., \& King-Smith, P. E. (1986). Red-green mixture thresholds in congenital and acquired color defects. Vision Research, 26, 1083-1097. doi:10.1016/0042-6989(86)90043-X

Shin, Y. J., Park, K. H., Hwang, J. M., Wee, W. R., \& Lee, J. H. (2007). A new color vision test to differentiate congenital and acquired color vision defects. Ophthalmology, 114, 1341-1347. doi:10.1016/j. ophtha.2006.10.030

Shin, Y. J., Park, K. H., Hwang, J. M., Wee, W. R., Lee, J. H., Lee, I. B., \& Hyon, J. Y. (2014). A novel color vision test for detection of diabetic macular edema. Investigative Ophthalmology and Visual Science, 55, 25-32. doi:10.1167/iovs.13-11698

Smith, V. C., Van Everdingen, J. A., \& Pokorny, J. (1991). Sensitivity of arrangement tests as evaluated in normals at reduced levels of illumination. In Colour Vision Deficiencies $X$ (pp. 177-185). New York, NY: Springer.

Tahir, H. J., Murray, I. J., Parry, N. R. A., \& Aslam, T. M. (2014). Optimisation and assessment of three modern touch screen tablet computers for clinical vision testing. PLoS ONE, 9, e95074. doi: 10.1371/journal.pone.0095074

Turpin, A., Lawson, D. J., \& McKendrick, A. M. (2014). PsyPad: A platform for visual psychophysics on the iPad. Journal of Vision, 14, 16. doi:10.1167/14.3.16

Verriest, G., Buyssens, A., \& Vanderdonck, R. (1963). Etude quantitative de l'effet qu'exerce sur les résultats de quelques tests de la discrimination chromatique une diminution non sélective du niveau d'un éclairage. Revue d'Optique, 3, 105-119.

Verriest, G., Vandevyvere, R., \& Vanderdonck, R. (1962). Nouvelles recherches se rapportant à l'influence du sexe et de l'age sur la discrimination chromatique, ainsi qu'à la signification pratique des résultats du test 100 hue de Farnsworth-Munsell. Revue d'Optique, Théorique et Instrumentale, 41, 499-509.

Wang, P., \& Nikolic, D. (2011). An LCD monitor with sufficiently precise timing for research in vision. Frontiers in Human Neuroscience, 5, 85. doi:10.3389/fnhum.2011.00085

Zhang, Y., Li, L., Zhang, X., \& Xi, Q. (2008). Temperature effects on photoluminescence of YAG:Ce3+ phosphor and performance in white light-emitting diodes. Journal of Rare Earths, 26, 446-449. doi:10.1016/S1002-0721(08)60115-5 